\title{
EDUCAÇÃO INFANTIL E GESTÃO: ABORDAGENS TEÓRICAS SOBRE LEGISLAÇÃO
}

\author{
Rúbia Borges \\ Universidade do Sul de Santa Catarina \\ rubiab10@hotmail.com
}

\section{Resumo}

Este trabalho tem por objetivo investigar as abordagens teóricas referentes à creche e gestão, considerando a Educação Infantil para diferentes públicos, como as crianças e bebês na perspectiva da infância. De abordagem qualitativa, esta pesquisa é bibliográfica, refletindo sobre os documentos oficiais que versam sobre o tema. O desenvolvimento da pesquisa ocorreu por meio de análise da legislação educacional, iniciando pela Constituição Federal (CF), Lei de Diretrizes e Bases (LDB), Diretrizes Curriculares Nacionais para a Educação Infantil e Plano Nacional de Educação (PNE). Os resultados apontam para uma legislação generalista, que permite certa autonomia na educação. Contudo, existe a necessidade de aprofundamento de estudos teóricos e práticos sobre a realidade das instituições que dela se ocupam para que seja possível oferecer educação de qualidade e que atenda às necessidades do público destas instituições.

Palavras-chave: Educação Infantil. Gestão. Legislação Educacional.

\section{CHILD EDUCATION AND MANAGEMENT: THEORETICAL APPROACHES ON LEGISLATION}

\begin{abstract}
The aim of this work was to investigate theoretical approaches regarding to daycare centers and management, considering childhood education for different audiences, such children and babies on the childhood perspective. On qualitative approach, this research is bibliographical and reflects on official documents about the theme. The development of this research occurred through analysis on educational Brazilian laws, starting by the Federal Constitution (FC), Law of Guidelines and Bases for National Education (LGB), National Curriculum Guidelines and the Education National Plan (ENP). The results point to a generalist legislation that allow certain autonomy on the education. However, there is the need to deepen theoretical and practical studies on the reality of institutions which have the education as the paramount purpose, in order to offer education with quality and attending to the needs from the audience in these institutions.
\end{abstract} Keywords: Childhood Education. Management. Education law.

\section{EDUCACIÓN INICIAL Y GESTIÓN: ENFOQUES TEÓRICOS SOBRE LA LEGISLACIÓN}

\section{Resumen}

Este estudio tiene como objetivo investigar los enfoques teóricos relacionados con el cuidado y manejo del niño, teniendo en cuenta la educación inicial para diferentes públicos, como los niños y los bebés en la perspectiva de la infancia. enfoque cualitativo, esta investigación es la literatura, lo que refleja en los documentos oficiales que se ocupan de la materia. El desarrollo de la investigación se llevó a cabo mediante el análisis de la legislación educativa, empezando por la Constitución Federal (CF), Ley de Directrices y Bases (LDB), Directrices Curriculares Nacionales para la Educación Inicial y Plan Nacional de Educación (PNE). Los resultados apuntan a una ley general, que permite una cierta autonomía en la educación. Sin embargo, existe la necesidad de realizar más estudios teóricos y prácticos sobre la realidad de las instituciones que se ocupan de modo que se puede brindar una educación de calidad que responda a las necesidades del público de estas instituciones.

Palabras clave: Educación Infantil. Gestión. La legislación Educativa. 
Educação infantil e gestão: abordagens teóricas sobre legislação

\section{INTRODUÇÃO}

Em nosso país, nos últimos anos, a educação vem apresentando significativo avanço no que diz respeito à legislação. A hierarquia legislativa vem sendo atualizada, como pode ser constatado por meio dos Planos Nacionais de Educação, os quais estão recebendo colaboração dos profissionais em exercício por meio de discussões coletivas, bem como das inúmeras emendas constitucionais utilizadas para atualização dos textos da Carta Magna. Além destes, as Diretrizes Curriculares para a Educação Infantil buscam nortear a organização de propostas pedagógicas para a Educação Infantil (EI), articulando-se às Diretrizes Curriculares Nacionais da Educação Básica, e também orientar políticas públicas para este nível de ensino, que corresponde à primeira etapa da Educação Básica (BRASIL, 2010).

Constatada a existência da legislação específica, surgiu a questão de pesquisa para esta investigação: quais abordagens teóricas referentes à creche e gestão são trazidas pela legislação vigente, considerando a Educação Infantil para diferentes públicos, como as crianças e bebês, na perspectiva da infância?

Para a realização desta pesquisa, foi analisada a legislação que versa sobre a educação, buscando obedecer a sua hierarquia: primeiro foram buscadas as concepções acerca do tema na Carta Magna, depois na Lei de Diretrizes e Bases, nas Diretrizes Curriculares para a Educação Infantil e no Plano Nacional de Educação. Embora se reconheça que estes não são os únicos documentos legais disponíveis e nem que apenas estes são imprescindíveis, são eles que norteiam as políticas e documentos derivados, como os que concernem os estados e municípios e, por fim, os Projetos Políticos Pedagógicos das escolas. Abordar todos os documentos, além de demandar maior tempo, implicaria uma delimitação específica de estudo. Optou-se, portanto, por uma abordagem de alcance nacional, possibilitando subsídio a outros trabalhos.

\section{Breve olhar sobre a legislação brasileira}

A legislação brasileira, no que diz respeito à educação, vem registrando grandes avanços desde a promulgação da última carta magna. O capítulo III da Constituição Federal (CF) - Da Educação, Da Cultura e Do Desporto, Seção I - Da Educação, aponta a "educação básica obrigatória e gratuita dos 4 (quatro) aos 17 (dezessete) anos de idade, assegurada inclusive sua oferta gratuita para todos os que a ela não tiveram acesso na idade própria” (BRASIL, 1988 ${ }^{1}$ ). Em seu inciso Art. 208, a mesma lei aponta que "o dever do Estado com a educação será efetivado mediante a

${ }^{1}$ Redação dada pela Emenda Constitucional n ${ }^{\circ} 59$, de 2009. 
garantia de: [...] IV - educação infantil ${ }^{2}$, em creche e pré-escola, às crianças até 5 (cinco) anos de idade (BRASIL, 19883).

O artigo 210, parágrafo $2^{\circ}$, preconiza que “os Municípios atuarão prioritariamente no ensino fundamental e na educação infantil” (BRASIL, 1988²). Ainda, é a própria Constituição Federal que, por meio de seu Art. 214, preconiza que se

\begin{abstract}
estabelecerá o plano nacional de educação, de duração decenal, com o objetivo de articular o sistema nacional de educação em regime de colaboração e definir diretrizes, objetivos, metas e estratégias de implementação para assegurar a manutenção e desenvolvimento do ensino em seus diversos níveis, etapas e modalidades por meio de ações integradas dos poderes públicos das diferentes esferas federativas (BRASIL, $\left.1988^{5}\right)$.
\end{abstract}

A carta Magna ainda versa sobre o piso salarial, investimentos, entre outros, que não são objetos de investigação neste estudo. O objeto de estudo deste trabalho centra-se no que versa o capítulo II, Da União que, em seu Art. 22 informa que "compete à União legislar sobre: [...] XXIV - diretrizes e bases da educação nacional" (BRASIL, 1988). E é a esta, portanto, que a continuidade da pesquisa se remete.

\title{
Lei de Diretrizes e Bases da Educação Nacional
}

O Portal do Ministério da Educação (MEC) traz traços históricos importantes sobre a Lei de Diretrizes e Bases - LDB. De 1948 a 1961 foram longos 13 anos de debate até a aprovação da primeira Lei de Diretrizes e Bases da Educação (LDB). Um dos maiores empasses foi à disciplina de ensino religioso, facultativo nas escolas públicas, tendo como ponto de partida neste momento a separação entre o estado e a Igreja. (BRASIL, MEC).

O texto ainda aponta para uma nova versão em 1971, onde o ensino passa a ser obrigatório dos sete aos 14 anos. Tendo no primeiro e segundo grau um currículo comum e prevendo uma parte diversificada de acordo com as diferenças regionais.

A mais nova LDB, ainda em vigor, foi implantada em 1996, e trouxe "diversas mudanças às leis anteriores, com a inclusão da educação infantil (creches e pré-escola). A formação

\footnotetext{
${ }^{2}$ Neste trabalho manteve-se a grafia com iniciais minúsculas para os níveis de educação apenas quando se trata de citação direta, visto que não há uniformidade em seu uso para todos os documentos e, como nível de educação, entende-se que a grafia apropriada seja com início em maiúsculas.

${ }^{3}$ Redação dada pela Emenda Constitucional no 53, de 2006.

${ }^{4}$ Redação dada pela Emenda Constitucional no 14, de 1996.

${ }^{5}$ Redação dada pela Emenda Constitucional no 59, de 2009.
} 
Educação infantil e gestão: abordagens teóricas sobre legislação

adequada dos profissionais da educação básica também foi priorizada com um capítulo específico para tratar do assunto" (BRASIL, MEC).

A LDB 9394/96, em seu capítulo I, Art. 21, define a composição dos níveis escolares em Educação Básica e Superior, sendo a primeira formada pela educação infantil, ensino fundamental e ensino médio (BRASIL, 1996).

A Seção II da LDB trata da Educação Infantil que em seus artigos define a educação infantil como a primeira etapa da educação básica tendo como finalidade o desenvolvimento da criança em sua integralidade até os seis anos em ação indissociável com a família e a comunidade. Define as divisões de idade nas creches ou entidades equivalentes, e em seguida, também define o acompanhamento e registro do desenvolvimento das crianças, sem o objetivo de promoção. (BRASIL, 1996).

No título IV, intitulado Da organizaçãa da Educação Nacional, em seu Art. $8^{\circ}$, observa-se que deve existir uma colaboração entre Estados, Distrito Federal e os Municípios que nortearão os currículos e conteúdos de modo a assegurar uma formação básica comum. Da mesma forma estabelece o oferecimento da Educação Infantil em creches e pré-escolas, e que deverá respeitar as normas comuns do seu sistema de ensino e terão alguns critérios, entre eles: elaborar e executar a sua proposta pedagógica, administrar seus recursos de pessoal e financeiro, assegurar o cumprimento de dias e horas letivas e atentar pelo cumprimento do plano de trabalho de cada docente, cumprindo assim com previsto na legislação.

Observa-se, portanto, que a LDB fixa normas gerais, mas dá liberdade às escolas. É necessário, assim, recorrer às Diretrizes Curriculares Nacionais para a Educação Infantil para que se desenhe, de maneira mais precisa o norte deste nível de educação.

\section{Diretrizes Curriculares Nacionais para a Educação Infantil}

A Resolução no 5, de 17 de dezembro de 2009 fixou as Diretrizes Curriculares Nacionais para a Educação Infantil. Os objetivos do documento foram "estabelecer as Diretrizes Curriculares Nacionais para a Educação Infantil a serem observadas na organização de propostas pedagógicas na educação infantil”' (BRASIL, 2010, p. 11).

Neste documento é possível encontrar as primeiras definições sobre Educação Infantil, criança, currículo e proposta pedagógica. Onde se reafirma a Educação Infantil como a primeira etapa da educação básica, oferecida em creches e pré-escolas, às quais ficam claros os objetivos dos espaços, sendo estas instituições não domésticas que constituem estabelecimentos 
educacionais públicos ou privados. Estes com objetivos de educar e cuidar de crianças de 0 a 5 anos de idade no período diurno, em jornada integral ou parcial, regulados e supervisionados por órgão competente do sistema de ensino e submetidos a controle social. Ficando neste sentido, evidente o dever do Estado garantir a oferta de Educação Infantil pública, gratuita e de qualidade, sem requisito de seleção (BRASIL, 2010).

Ainda neste mesmo documento, a criança é vista como um sujeito histórico e de direitos que nas interações, relações e práticas cotidianas que vivencia constrói a sua identidade, através também, da coletividade quando ela brinca, imagina, fantasia, observa, experimenta, narra, aprende através de todas as relações com o seu redor, com a natureza e com o outro.

Por currículo, o mesmo documento define um "conjunto de práticas que buscam articular as experiências e os saberes das crianças com os conhecimentos que fazem parte do patrimônio cultural, artístico, ambiental, científico e tecnológico, de modo a promover o desenvolvimento integral de crianças de 0 a 5 anos de idade” (BRASIL, 2010, p. 12).

Já a

[...] proposta pedagógica ou projeto político pedagógico é o plano orientador das ações da instituição e define as metas que se pretende para a aprendizagem e o desenvolvimento das crianças que nela são educados e cuidados. É elaborado num processo coletivo, com a participação da direção, dos professores e da comunidade escolar (BRASIL, 2010, p. 13).

Embora o currículo e a proposta pedagógica não sejam objetos de investigação neste estudo, ambas as definições são consideradas pertinentes para este trabalho, dadas suas implicações no nível de educação estudado.

As Diretrizes Curriculares Nacionais para a Educação Infantil ainda versam sobre a matrícula, frequência e vagas:

\footnotetext{
É obrigatória a matrícula na Educação Infantil de crianças que completam 4 ou 5 anos até o dia 31 de março do ano em que ocorrer a matrícula. As crianças que completam 6 anos após o dia 31 de março devem ser matriculadas na Educação Infantil. A frequência na Educação Infantil não é pré-requisito para a matrícula no Ensino Fundamental. As vagas em creches e pré-escolas devem ser oferecidas próximas às residências das crianças (BRASIL, 2010, p. 15).
}

Quanto à jornada, quando de quatro horas é considerada parcial, e integral quando é igual ou superior a sete horas.

As Diretrizes também abordam os princípios éticos, a indissociabilidade entre cuidado e educação, e que as propostas pedagógicas devem garantir, primordialmente, que a criança tenha acesso de apropriação de conhecimentos e aprendizagens de diferentes linguagens, assim como 
Educação infantil e gestão: abordagens teóricas sobre legislação

também, o direito à saúde, à liberdade, à confiança, ao respeito, à dignidade, à brincadeira, à convivência e interação com outras crianças, e principalmente, à proteção. (BRASIL, 2010).

Além destes aspectos, o documento versa sobre práticas pedagógicas na Educação Infantil, proposta pedagógica com crianças indígenas, entre outros fatores, mostrando-se um documento de abordagem ampla, mas procurando atender necessidades específicas deste nível de educação.

Buscou-se, então, o Plano Nacional de Educação para finalizar a fundamentação da pesquisa.

\section{Plano Nacional de Educação: breve olhar sobre as metas para a Educação Infantil}

De acordo com Santana (2014, p. 01), o Plano Nacional de Educação entrou em vigor em junho de 2014 e valerá por 10 anos, é reconhecida como uma lei ordinária, prevista pela CF. Todos os planos estaduais e municipais de Educação devem ser criados ou adaptados em consonância com as diretrizes e metas estabelecidas pelo PNE desde o momento de sua vigência.

Entre as metas, a primeira já diz respeito à Educação Infantil: "Meta 1: universalizar, até 2016, a educação infantil na pré-escola para as crianças de 4 (quatro) a 5 (cinco) anos de idade e ampliar a oferta de educação infantil em creches, de forma a atender, no mínimo, 50\% (cinquenta por cento) das crianças de até 3 (três) anos até o final da vigência deste PNE” (BRASIL, 2014, p. $9)$.

O documento também enfatiza metas para portadores de necessidades especiais, mas estes não são foco deste trabalho.

Entre as estratégias para assegurar a meta 1, está previsto o levantamento da demanda por creche para a população até 3 anos, isto é, fortalecer o acompanhamento e o monitoramento do acesso e permanência das crianças na educação infantil em colaboração com as famílias e com os órgãos públicos de assistência social, saúde e proteção à infância. (Brasil, 2014).

Vale destacar que a meta 2 refere-se à universalização do "ensino fundamental de 9 (nove) anos para toda a população de 6 (seis) a 14 (quatorze) anos e garantir que pelo menos 95\% (noventa e cinco por cento) dos alunos concluam essa etapa na idade recomendada, até o último ano de vigência deste PNE” (BRASIL, 2014, p. 19).

Considera-se, portanto, a Educação Infantil até os cinco anos de idade, visto que dos seis em diante as crianças devem estar cursando o Ensino Fundamental. 


\section{Breve reflexão acerca da legislação}

Ao desenvolver a pesquisa para este estudo, observou-se uma constante atualização dos textos legislativos, que são citados nas notas de rodapé das seções: embora a Constituição de nosso país seja de 1988, desde então o texto vem sendo modificado por meio de Emendas Constitucionais. O mesmo se percebe na LDB: a Lei 12.796 de 2013 veio complementar o texto e dar nova redação a diversos aspectos. Além destes, também foi possível observar o cumprimento à determinação da Constituição Federal (CF) da criação dos Planos Nacionais de Educação (PNE), que vem sendo construídos de forma colaborativa.

Entretanto, o que se percebe, pela análise dos textos mencionados, é que há alguma divergência entre eles e, ainda, algumas lacunas a serem observadas e preenchidas.

É notório o esforço para o melhoramento dos textos legislativos, mas eles não parecem abordar o tema sob um ponto de vista único. A CF, por exemplo, menciona a "educação básica obrigatória e gratuita dos 4 (quatro) aos 17 (dezessete) anos de idade" (BRASIL, 1988); a LDB traça a Educação Infantil dos 0 aos 6 anos de idade no Art. 30 (BRASIL, 1996); As Diretrizes Curriculares Nacionais para a Educação Infantil estabelecem de 0 a 5 anos de idade (BRASIL, 2010), e o PNE, em suas estratégias, menciona programas para o desenvolvimento integral de crianças até os 3 anos de idade.

Podemos concluir que não há um limite bem definido do início da Educação Infantil nos textos legislativos e, ainda, que há sobreposição de idade, em alguns casos: se o Ensino Fundamental de nove anos inicia aos seis, como a Educação Infantil pode ir até os mesmos seis anos?

Outro aspecto a ser considerado é que a legislação não define etapas dentro da própria Educação Infantil, que motivaram esta pesquisa: por apresentar uma abordagem generalista, não estão claramente definidas concepções sobre infância, criança e bebê, por exemplo, mas os dois últimos termos, embora tratados como sinônimos demandam não apenas cuidados e educação específicos, mas instalações e treinamento também direcionados às suas necessidades.

A Educação Infantil é mencionada na CF, mas não é definida. A LDB traz que é a "primeira etapa da educação básica, tem como finalidade o desenvolvimento integral da criança até seis anos de idade, em seus aspectos físico, psicológico, intelectual e social, complementando a ação da família e da comunidade" (BRASIL, 1996), e define o ambiente para este nível de educação como creches ou equivalentes até os 3 anos, e pré-escolas dos 4 aos 6 . Considerando a 
Educação infantil e gestão: abordagens teóricas sobre legislação

LDB e o PNE, pode-se inferir, então, que os bebês frequentam as creches estão entre 0 e 3 anos, e as crianças da Educação Infantil são aquelas que estão entre os 4 e os 5 anos, visto que dos 6 anos em diante deverão estar no Ensino Fundamental, hoje com 9 anos de duração. Também é importante mencionar que a obrigatoriedade da matrícula na Educação Infantil, segundo as Diretrizes Curriculares Nacionais da Educação Básica, é para “crianças que completam 4 ou 5 anos até o dia 31 de março do ano em que ocorrer a matrícula. As crianças que completam 6 anos após o dia 31 de março devem ser matriculadas na Educação Infantil” (BRASIL, 2010, p. 15). Questiona-se, portanto, se estes últimos não deveriam estar matriculados no Ensino Fundamental.

Ademais, ainda se questiona o fato de as Diretrizes Curriculares Nacionais da Educação Básica afirmar que, "além das exigências dessas diretrizes, devem também ser observadas a legislação estadual e municipal atinentes ao assunto, bem como as normas do respectivo sistema” (BRASIL, 2010, p. 11), pois, conforme atesta Santana (2014, p. 01), "a partir do momento em que o PNE começa a valer, todos os planos estaduais e municipais de Educação devem ser criados ou adaptados em consonância com as diretrizes e metas estabelecidas por ele". Como atender diferentes textos que versam sobre o mesmo tema, dispostos em períodos diferentes, e que parecem não conversar entre si em alguns aspectos?

A breve reflexão empreendida trouxe, ainda, outros questionamentos: quais implicações das particularidades da Educação Infantil, no que concerne aos diferentes públicos, como crianças e bebês, para a gestão das entidades que se dedicam a este nível de educação?

O que se depreende da investigação é que o fato de apenas fixar normas gerais e promover liberdade às escolas reflete em uma necessidade de aprofundamento de estudos teóricos e práticos para este nível de Educação.

\section{CONSIDERAÇÕES FINAIS}

As abordagens teóricas referentes à creche e gestão trazidas pela legislação vigente, considerando a Educação Infantil para diferentes públicos, como as crianças e bebês, na perspectiva da infância, vêm apresentando avanços no que concerne a educação, de maneira geral.

Os textos vigentes vêm recebendo novas redações por meio de Emendas e leis específicas. Contudo, o lapso de tempo entre a edição dos textos parece contribuir para que alguns pontos não sejam incisivamente claros, como a definição da idade das crianças que devem 
Educação infantil e gestão: abordagens teóricas sobre legislação

estar matriculadas na Educação Infantil e no Ensino Fundamental, quando da idade limite da primeira para o segundo.

Outro aspecto a ser considerado é certa generalização acerca do público da Educação Infantil: crianças e bebês não recebem menção separada, mas apresentam realidades e necessidades distintas. Percebe-se, portanto, que o caráter generalista da legislação deixa sobre os profissionais da educação as responsabilidades da efetivação desta educação. Também é possível inferir a existência de uma demanda de aprofundamento de estudos teóricos e práticos sobre a realidade das instituições que dela se ocupam para que seja possível oferecer educação de qualidade e que atenda às necessidades do público destas instituições.

Ao realizar esta pesquisa, foi analisada a legislação que versa sobre a educação, obedecendo a sua hierarquia. A primeira análise debruçou-se sobre as concepções acerca do tema na CF. Por meio dela percebe-se um capítulo inteiro dedicado à Educação, cultura e desporto. Neste capítulo encontra-se a obrigatoriedade e gratuidade da Educação Básica, que deve ir dos 4 aos 17 anos, mesmo para aqueles que não conseguiram frequentá-la na idade apropriada. Mais adiante, a CF preconiza o dever do Estado para as crianças até 5 anos, efetivado pela garantia de Educação Infantil, creche e pré-escola e, ainda, que os municípios terão prioridade de atuação no Ensino Fundamental e na Educação Infantil. Também é a CF que estabelece o PNE, além de outras matérias a respeito da Educação. A União legisla sobre as Diretrizes e Bases da Educação Nacional e, por esta razão, foi a lei seguinte analisada neste trabalho, mantendo a hierarquia.

A primeira LDB foi debatida durante 13 anos (1948-1961), e dez anos depois já havia uma segunda versão. A primeira tornou o ensino religioso facultativo, e a segunda previu a obrigatoriedade do ensino até os 14 anos, além da parte diversificada nos currículos, considerando diferenças regionais. A terceira versão e ainda em vigor, a LDB 9394/96 trouxe a inclusão da Educação Infantil, contando com creches e pré-escola, definindo a Educação Básica e Superior.

Em seguida, foram analisadas as Diretrizes Curriculares Nacionais para a Educação Infantil, documento que define Educação Infantil, criança, currículo e proposta pedagógica, além da obrigatoriedade de matrícula das crianças na Educação Infantil, frequência, vagas e jornada. As Diretrizes [...] ainda abordam a indissociabilidade entre cuidado e educação.

Por fim, buscou-se o Pano Nacional de Educação (PNE), pois é o documento de publicação mais recente. A primeira meta do PNE já diz respeito à Educação Infantil, por meio da qual se deve universalizar a Educação Infantil na pré-escola para as crianças de 4 (quatro) a 5 (cinco) anos de idade, além de ampliar a oferta de Educação Infantil em creches até 2016. A meta 
Educação infantil e gestão: abordagens teóricas sobre legislação

visa a atender pelo menos 50\% (cinquenta por cento) das crianças de até 3 (três) anos até o final da vigência do PNE.

Ainda são definidas estratégias para o alcance da meta, como o levantamento da demanda, para a população até 3 anos, por creche. Por deverem estar matriculadas no Ensino Fundamental as crianças com seis anos de idade, é considerada Educação Infantil a oferta até os cinco anos de idade.

Estes documentos não são os únicos a nortearem o ensino nesta esfera da educação, mas guiam as propostas curriculares de estados e municípios, das quais derivam os projetos políticos pedagógicos das escolas.

Os resultados deste estudo apontam para a necessidade de aprofundamento de pesquisas sobre o tema, considerando o Estatuto da Criança e do Adolescente, por exemplo, e a delimitação de Estado e Município para a verificação de como se processa a realidade de ensino nas instituições de Educação Infantil, de modo a contribuir com a classe docente e, consequentemente com os discentes da EI.

\section{REFERÊNCIAS}

BAUER, M. W.; GASKELL, G. Pesquisa qualitativa com texto, imagem e som. Petrópolis: Vozes, 2010.

BRASIL, Ministério da Educação. Secretaria de Educação Básica. Diretrizes curriculares nacionais para a educação infantil / Secretaria de Educação Básica. - Brasília: MEC, SEB, 2010.

BRASIL, Ministério da Educação. História. Disponível em:

$<$ http://portal.mec.gov.br/index.php?option $=$ com_content\&view $=$ article\&id $=2$ :historia\&catid =97:omec\&Itemid=171>. Acesso em: 31 ago. 2015.

BRASIL, Ministério da Educação. Lei de Diretrizes e Bases da Educação Nacional. 1996. Disponível em: <http://portal.mec.gov.br/arquivos/pdf/ldb.pdf>. Acesso em 20 jul. 2015.

BRASIL, Presidência da República. Casa Civil. Constituição da República Federativa do

Brasil. Disponível em: <http://www.planalto.gov.br/ccivil_03/constituicao/constituicao.htm>. Acesso em 20 jul. 2015.

BRASIL, Ministério da Educação. Planejando a Próxima Década: Conhecendo as 20 Metas do Plano Nacional de Educação. Disponível em: < http://pne.mec.gov.br/images/pdf/pne_conhecendo_20_metas.pdf>. Acesso em 20 jul. 2015.

GIL, A. C. Como elaborar projetos de pesquisa. São Paulo: Atlas, 2010. 
Educação infantil e gestão: abordagens teóricas sobre legislação

SANTANA, A. E. PNE: 10 perguntas para tirar suas dúvidas sobre o Plano Nacional de Educação. 2014. Portal EBC. Disponível em:

<http://www.ebc.com.br/educacao/2014/07/entenda-o-pne>. Acesso em: 22 jul. 2015. 